\title{
Production of Carbon Foams from Rice Husk
}

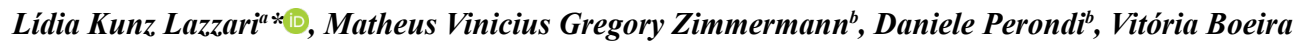

Zampieri $^{b}$, Ademir José Zattera ${ }^{b}$, Ruth Marlene Campomanes Santana ${ }^{a}$

\author{
${ }^{a}$ Programa de Pós-Graduação em Engenharia de Minas, Materiais e Metalurgia, Universidade Federal \\ do Rio Grande do Sul, Porto Alegre, RS, Brasil \\ ${ }^{b}$ Programa de Pós-Graduação em Engenharia de Processos e Tecnologias, Universidade de Caxias do \\ Sul, Caxias do Sul, RS, Brasil
}

Received: July 12, 2019; Revised: September 19, 2019; Accepted: September 25, 2019

\begin{abstract}
The production of a material with rigid, multifunctional three-dimensional porous structure at a low cost is still challenging to date. In this work, a light and rigid carbon foam was prepared using rice husk as the basic element through a simple fermentation process followed by carbonization. For the fermentation process, the amount of biological yeast $(7.5 \mathrm{~g}$ for the carbon foam CA-1P and $5 \mathrm{~g}$ for the carbon foam CA-2P) was used to evaluate its influence on the morphology of the foams. In order to prove that the heat treatment made in the foam alters the hydrophilic character of the rice husk foam, a chemical treatment with steam deposition was carried out. The foams were characterized by the following analyzes: apparent density, micrograph, thermogravimetry, contact angle, water sorption capacity and thermal conductivity. Visually, the CA-1P foams presented a structure with larger pores due to the greater amount of yeast used in its formulation. The heat treatment of rice potato foams proved to be as efficient as the chemical treatment for water contact angle above $90^{\circ}$, proving the ability of the foams to repel water/moisture. The thermal conductivity of the foams $\left(0.029\right.$ and $0.026 \mathrm{~W} \mathrm{~m}^{-1} \mathrm{~K}^{-1}$ for CA-1P and CA-2P, respectively) was close to the conductivity of polyurethane foams $\left(0.032 \mathrm{~W} \mathrm{~m}^{-1} \mathrm{~K}^{-1}\right)$. Thus, the method used in the production of the carbon foams produced from the rice husk proved to be effective. In addition, the foams produced have the potential to be used for thermal insulation.
\end{abstract}

Keywords: Carbon foams, rice husk, thermal insulation.

\section{Introduction}

The use of agricultural by-products as a source of raw material for the development of added-value products and as an alternative energy source reduces dependence on fossil sources. In addition it is a low cost and sustainable solution ${ }^{1,2}$. Biomass is a qualified raw material for the preparation of carbonaceous materials, since it is available in abundance, besides being a renewable resource. Different materials based on biomass are being studied for applications in different areas, such as: composite rice husks and expanded cork granules and recycled tire rubber for civil construction ${ }^{3}$; activated carbon produced from bamboo ${ }^{4}$; carbon aerogels produced from starch as electrode material for supercapacitors ${ }^{5}$; barley straw ${ }^{6}$ e cellulose ${ }^{7}$ as adsorbents for the removal of oils, among others.

Recently, biomass-based carbon foams, such as wheat flour ${ }^{8}$ e tannins ${ }^{9}$, were successfully manufactured by different methods, such as: lyophilization, hydrothermal treatment and direct carbonization. Pyrolysis is a promising way to convert this biomass into high added value products. The pyrolysis process consists of the thermal decomposition of the organic matter contained in the biomass, under a certain

*e-mail: 1klazzar@ucs.b temperature and in the total or partial absence of oxygen in: a gaseous, solid (biochar) and liquid fraction (bio-oils) ${ }^{8,10}$.

Among the positives aspects of the carbon foams, are their thermal stability, low density and thermal expansion, good resistance to thermal stress and shock, and a relatively low cost. An important property obtained after the pyrolysis process of the foams is hydrophobicity. This is a result of the loss of oxygen and hydrogen by the dehydration and decarboxylation reactions during the pyrolysis process. They can be applied in thermal insulation for high temperatures, filters, porous electrodes, thermal management, among others $^{9,11,12}$.

Carbon foams obtained from the pyrolysis of foams produced from commercial Mimosa peel tannin extract and exfoliated graphite were studied by Jana et al. ${ }^{9}$. The authors showed that the porosity and thermal conductivity of the foams were influenced by the density of the foams, which varies according to the amount of exfoliated graphite used. That is, the higher the density, the lower is the porosity and the higher is the thermal conductivity.

A simple and low cost methodology for the production of carbon foams was presented by Yuan et al. ${ }^{8}$. The authors produced carbon foams from the pyrolysis of foams made from wheat flour. The pyrolysis process chosen by the authors is inexpensive and provides the foam with a structure that is both appropriate mechanically and thermally stable. The 
porous structure of the material, a determinant factor for the properties of the foam, was controlled based on the amount of water and yeast used. According to the authors, the specific mass and compressive strength are dependent on the amount of yeast used. The higher the amount of yeast used, the greater are the pores formed by decreasing the density of the foams. In addition, the carbon foams exhibited thermal conductivity between 0.09 and $0.17 \mathrm{~W} \cdot \mathrm{m}^{-1} \cdot \mathrm{K}^{-1}$. The authors concluded that this method can be widely applied to other materials with structures that require thermal conductivity and low density.

The rice husk represents about $20 \%$ of the bulk volume of rice. It is a woody bark composed of cellulose, hemicellulose, lignin and inorganic materials. Of this inorganic fraction, about $90-95 \%$ is of hydrated silica, contemplating of 13 to $29 \%$ of the total of the bark. Due to its characteristics such as abrasiveness and hardness, the rice husk has no commercial value and is discarded in rural areas. However, it presents as a potential precursor in the production of activated carbon due to its physicochemical and biochemical properties ${ }^{8,13}$.

The scientific contribution of this study is the development of carbon foams from the pyrolysis of wood foam produced with the rice husk based on the methodology used by Yuan et al. ${ }^{8}$. Pyrolysis was used as a method of hydrophobizing the foam surface. The comparison with the traditional silane vapor deposition method was performed to verify the efficiency of the method proposed in the present work. Thermal, chemical and morphological properties of these foams were studied in order to evaluate their use as thermal insulation.

\section{Materials and Methods}

\subsection{Materials}

The raw materials used in the production of the foams were: rice husk, wheat flour, soybean oil, water and dry yeast (these are common for bread making). Triethoxyvinylsilane (VTES) was purchased from Sigma-Aldrich.

\subsection{Wood development}

The process used for the production of rice husk foams was based on the fermentation process presented by Yuan et al. ${ }^{8}$, in which the authors associated this process with the process of bread production. Figure 1 shows the flowchart of the production process of the rice husk foams and carbon foams. The rice husk was used as raw material in the production of the foams in order to use an agricultural residue generated in abundance during the production of rice.

Initially, the rice husk (CA) was dried at $105^{\circ} \mathrm{C}$ for $24 \mathrm{~h}$ and was comminuted in a knife mill using a $1 \mathrm{~mm}$ sieve. The organic yeast ( $7.5 \mathrm{~g}$ for CA-1 foam and $5 \mathrm{~g}$ for CA-2 foam) was then dissolved in $130 \mathrm{~g}$ of deionized water at $40^{\circ} \mathrm{C}$ under magnetic stirring. After completely dissolved, the mixture was poured into $150 \mathrm{~g}$ of wheat flour, $100 \mathrm{~g}$ of rice husk powder and approximately $4 \mathrm{~g}$ of soybean oil (used to "bind" the dough). The components were mixed for 10 minutes in a planetary mixer until a homogeneous mass was formed, which was the fermented for about $60 \mathrm{~min}$ at $35^{\circ} \mathrm{C}$ for the formation of porous structures. The foam was baked in an oven at $180^{\circ} \mathrm{C}$ for $40 \mathrm{~min}$ and then dried for $24 \mathrm{~h}$ at $80^{\circ} \mathrm{C}$.
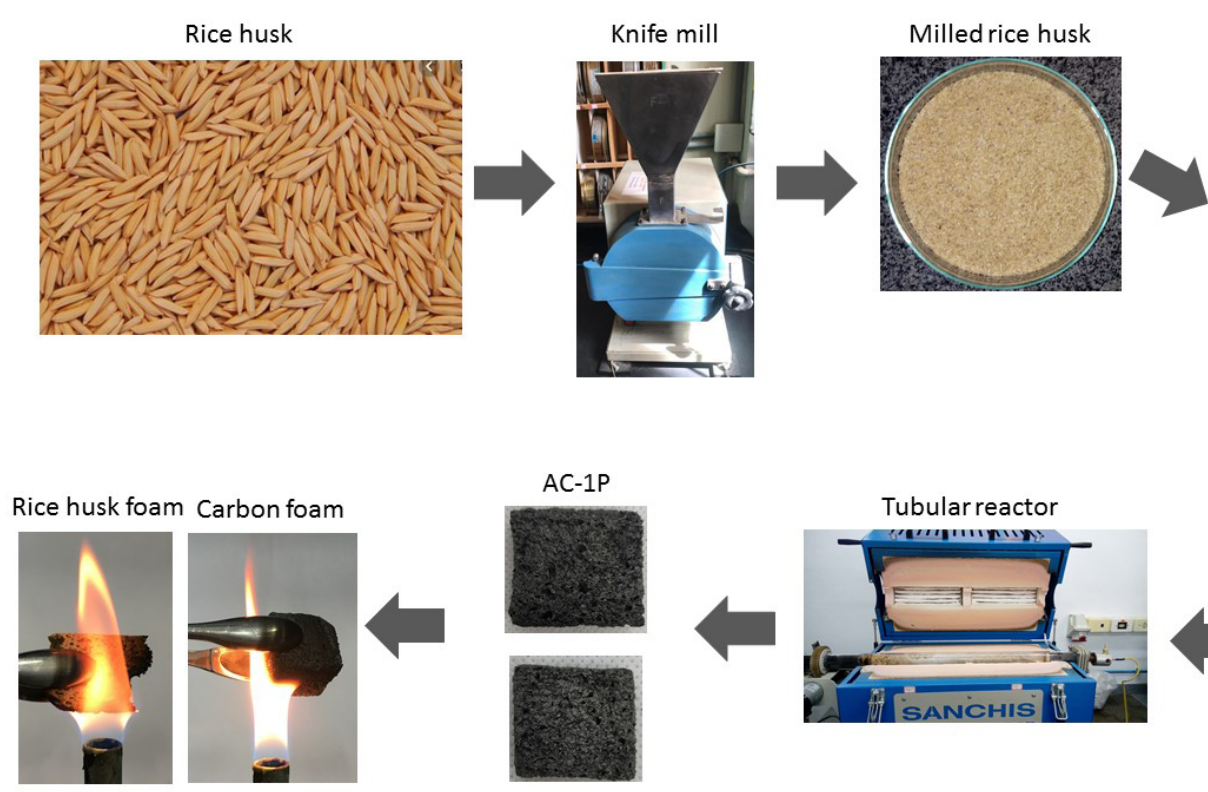
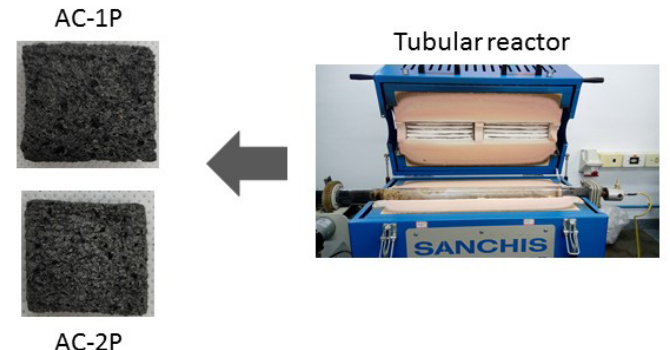

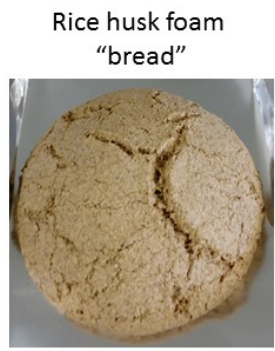

AC-1

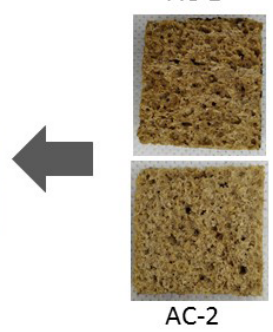

Figure 1. Flowchart of the production of rice husk foams and carbon foams. Caption: CA-1 (7.5 g yeast foam), CA-1P (CA-1 foam after pyrolysis), CA-2 (5.0 g yeast foam) and CA-2P (CA-2 foam after pyrolysis). 
The pyrolysis of the foams was carried out in a cylindrical quartz reactor that operates in a batch system, this reactor is described in detail by Perondi et al. ${ }^{14}$. The reactor was initially fed with approximately $5.5 \mathrm{~g}$ of wood foam. During the pyrolysis reaction, nitrogen gas $\left(\mathrm{N}_{2}\right)$ was used, with a flow rate of $0.15 \mathrm{~L} \mathrm{~min}^{-1}$. The heating rate used was $5{ }^{\circ} \mathrm{C}$ $\mathrm{min}^{-1}$ until the final temperature was reached $\left(800^{\circ} \mathrm{C}\right)$. An isotherm time of $60 \mathrm{~min}$ at this temperature $\left(800^{\circ} \mathrm{C}\right)$ was used. Finally, the system was cooled under $\mathrm{N}_{2}$ flow at room temperature. Carbon foams were named CA-1P(CA-1 foam after pyrolysis) and CA-2P (CA-2 foam after pyrolysis).

\subsection{Surface treatment of foams}

In order to verify the efficiency of the pyrolysis process in the hydrophobicization of the foam surface, a silane vapor deposition was carried out. This method is effective for this application $^{15}$, as a way of comparing methods.

Triethoxyvinylsilane (VTES) was deposited onto the rice husk foams as a surface treatment in order to render the surface hydrophobic and thus moisture-absorption free. The samples were suspended, by a screen, in a beaker containing $4.0 \mathrm{~mL}$ of MTMS and isolated inside another beaker for $48 \mathrm{~h}$ in an oven at $70^{\circ} \mathrm{C}$. Carbon foams were named CA-1H (CA-1 foam after surface treatment) and CA-2H (CA-2 foam after surface treatment).

The water contact angle was measured on the foams to evaluate their degree of hydrophobicity. In the assay, a drop of distilled water was added at three random points on the surface of the foam. The image was recorded with a digital still camera and the images obtained were analysed by using Surftens.

In order to verify the effectiveness of surface treatment with VTES, a water absorption capacity test was performed according to ASTM F726-12 (2012). The foams were previously weighed and then placed in contact with the distillate water at $25^{\circ} \mathrm{C} \pm 2$. After 15 minutes they were suspended for $30 \mathrm{~s}$ to remove excess liquid and then re-weighed. The sorption capacity $\left(\mathrm{g} \mathrm{g}^{-1}\right)$ of water was calculated by the ratio of the mass ( $\mathrm{g}$ ) of the foam before and after the test. The test was realized in triplicate.

\subsection{Caracterization}

The percentage of cellulose, hemicellulose and lignin present in rice husk cellulose were quantified according to the TAPPI T222 om-02 (lignin) methodology and by the modified Van Soest method (cellulose and hemicellulose).

The apparent density of the foams was calculated by the mass $(\mathrm{g})$ to volume $\left(\mathrm{cm}^{3}\right)$ ratio, for five specimens.

The morphology was evaluated by using light microscopy in Meterk (China) optical microscope.

The infrared spectra of the foams were obtained on a Nicolet IS10 Thermo Scientific (USA) spectrometer using a universal attenuated total reflection (ATR) sampling accessory.
The absorbance was measured in the spectral range of 700 and $4000 \mathrm{~cm}^{-1}$, with 32 scans and a resolution of $4 \mathrm{~cm}^{-1}$.

The thermal properties of the foams were evaluated by thermogravimetry (TG), by using a Shimadzu model TGA-50, with a heating rate of $10{ }^{\circ} \mathrm{C} \mathrm{min}^{-1}$ and a heating flux of 30 to $800{ }^{\circ} \mathrm{C}$ under a nitrogen atmosphere $\left(\mathrm{N}_{2}\right)$ at the rate of $50 \mathrm{~mL} \mathrm{~min}^{-1}$.

The thermal conductivity of the foams was determined according to the standard NBR 15220-5 (2003). Samples with $50 \times 50 \times 20 \mathrm{~mm}$ width, length and thickness, respectively, were used in a total of 2 samples per analysis. The test was performed in a plate system where the temperature difference between the hot and cold plates is controlled. The test was conducted according to the adaptation of standard NBR 15220-5 (2003). The heat flux applied in the system was determined by measurements with Thermax ${ }^{\circledR}$ rock wool (density $0.032 \mathrm{~g} \mathrm{~cm}^{-3}$ ), which has a known thermal conductivity $\left(0.045 \mathrm{~W} \mathrm{~m}^{-1} \cdot \mathrm{K}^{-1}\right)$. The thermal conductivity was determined by the Fourier law.

\section{Results and Discussion}

\subsection{Caracterization of rice husk}

Rice husk is a fabric composed of three polymers: cellulose, hemicellulose and lignin. The composition of the rice husk showed a fraction of $41.16 \pm 0.52 \% \mathrm{w} / \mathrm{w}$ cellulose, $14.0 \pm 1.1 \% \mathrm{w} / \mathrm{w}$ hemicellulose and $19.02 \pm 0.14 \% \mathrm{w} / \mathrm{w}$ lignin. Second McKendry ${ }^{16}$, cellulose and hemicellulose are present in a larger amount than lignin, unlike forest residues. Still, there may be a wide variation for each component. For instance, cellulose ranges from $28.6 \%$ to $41.5 \%$, hemicellulose from $14.0 \%$ to $28.6 \%$ and lignin from $20.4 \%$ to $33.7 \%$, the variation depend on climatic conditions, agronomic management, soil type, among other parameters ${ }^{1}$.

In the pyrolysis process of this biomass the lignin is the main constituent of the biochar formed, becoming responsible for the adsorption process when the biochar is used for this application. Cellulose and hemicellulose are related to the low carbon content in the biochar, as they are responsible for the volatile fractions which enable the loss of a significant fraction of carbon during the pyrolysis process ${ }^{17}$.

The percentage of ash in the rice husk sample was $15.82 \pm 0.08 \% \mathrm{w} / \mathrm{w}$, whose cost is higher than in other biomasses. These values are close to other studies that also characterized rice husk, $14.8 \% \mathrm{w} / \mathrm{w}$ for Abu Bakar and Titiloye $^{18}$ and $16.9 \% \mathrm{w} / \mathrm{w}$ for Fang et al. ${ }^{19}$. These ashes have silicon dioxide $\left(\mathrm{SiO}_{2}\right)$ as main component, which can be presented in: crystalline form or amorphous form, very useful for different applications. According to Quispe et $\mathrm{al}^{1}$, the values of silicon dioxide in the ashes of rice husk vary from $87.4 \%$ to $91.4 \%$. Amorphous silica is reactive and can be used to improve concrete properties, as well as being used as a cementitious additive for the solidification of hazardous 
waste. In addition to ash, the sample also presented $9.62 \pm$ $0.57 \% \mathrm{w} / \mathrm{w}$ of moisture and $7.87 \pm 0.39 \% \mathrm{w} / \mathrm{w}$ of extractives.

According to Diniz ${ }^{20}$, the solid fraction obtained in the pyrolysis of the rice husk presents a high mineral content in comparison with other biomasses, in which approximately $40 \%$ of the coal obtained from the rice husk corresponds to inorganic material, mainly silica.

Figure 2 shows the FTIR spectrum of the rice husk and the attributions of the identified bands.

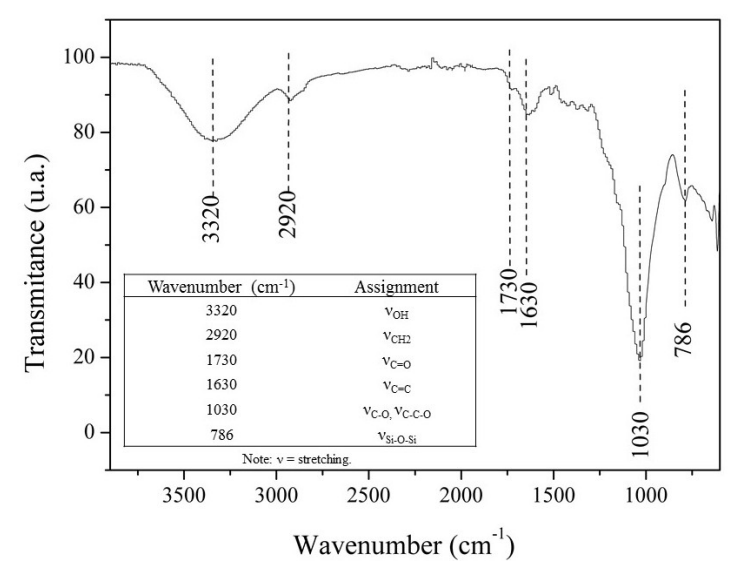

Figure 2. FTIR spectrum of rice husk.

The band at $3320 \mathrm{~cm}^{-1}$ is attributed to $\mathrm{OH}$ stretching vibrations related to the cellulosic material or water, the bands at $1030 \mathrm{~cm}^{-1}$ can be attributed to $\mathrm{CO}, \mathrm{C}=\mathrm{C}$ and $\mathrm{CCO}$ related to cellulose, hemicellulose and lignin $^{2,8}$.

The symmetrical and asymmetric stretching vibration bands seen between 3500 and $3000 \mathrm{~cm}^{-1}$ show the presence of moisture in the biomass structure and that the dehydration reactions occur during pyrolysis. In this region, there is also the presence of -OH groups, these stretch mainly due to the presence of silanols $(\mathrm{Si}-\mathrm{OH})$ that are adsorbed on the surface of the bark ${ }^{17,18}$.

Figure 3 shows the results for thermal analysis for the rice husk sample and the CA-1 (produced with $7.5 \mathrm{~g}$ yeast) and CA-2 (produced with 5.0 g yeast) samples.

Analyzing Figure 3 it is possible to notice that mass loss occurs below $100^{\circ} \mathrm{C}$, at which point the evaporation of water absorbed in the biomass structure takes place (8.4\%). The main region of mass loss can be observed between 200 and $370{ }^{\circ} \mathrm{C}$, with a mass loss of $43.8 \%$. For Ozsin \& Putun ${ }^{21}$ this region is called active pyrolysis with the release of organic and non-condensable gases. At $370^{\circ} \mathrm{C}$ the mass loss is about $25.9 \%$. This phase is also defined by the authors as passive pyrolysis, when a secondary decomposition of solid wastes occurs. In this region it is possible to observe two stages of mass loss, the first, from 200 to $300^{\circ} \mathrm{C}$, corresponds to the degradation of the hemicellulose and part of the cellulose. In the second stage, from $300^{\circ} \mathrm{C}$ onwards, lignin decomposes,

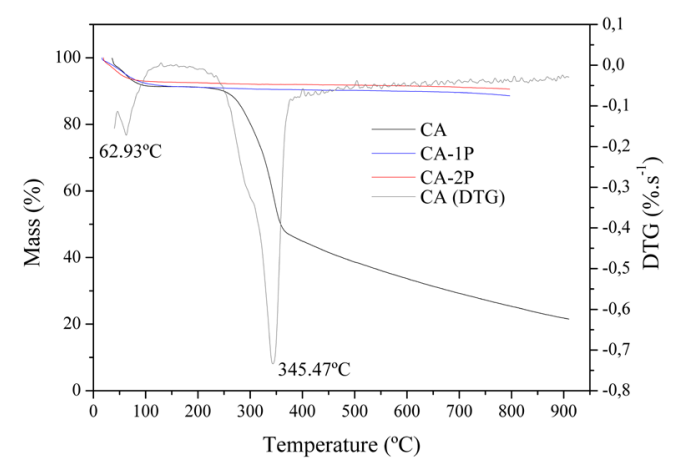

Figure 3. Thermogravimetry and thermogravimetry derived rice husk. Caption: CA-1 (7.5 g yeast foam) and CA-2 (5.0 g yeast foam).

showing a greater stability in relation to cellulose and hemicellulose.

According to Almeida ${ }^{13}$, due to the shape of the thermogravimetric curve and the temperatures involved in the thermal degradation of the rice husk, it can be considered richer in cellulose than lignin. These pyrolysis characteristics can be explained by the degradation patterns of cellulose, hemicellulose and lignin and their overlapping zones. It is known that the decomposition of hemicellulose and cellulose occurs in the temperature ranges of $200-350{ }^{\circ} \mathrm{C}$ and $200-500^{\circ} \mathrm{C}$, respectively. On the other hand, the decomposition of lignin occurs at a rather slow rate in relation to hemicellulose and cellulose, which covers a broader temperature range of $150-900{ }^{\circ} \mathrm{C}^{10,18}$.

Several authors ${ }^{12,17}$ also found this thermal degradation behavior for samples of rice husk. Since, in general, the total degradation of the biomass can be affected at temperatures between 600 and $800{ }^{\circ} \mathrm{C}$. The residual mass (ashes) was approximately $22 \%$, also in agreement with the other authors. According to Dunnigan et al. ${ }^{22}$, the high ash content in the rice husk $(21.5 \%)$, causes a reduction in the carbon content present in the biochar $( \pm 40 \%)$.

\subsection{Rice husk and carbon foams}

Figure 4 shows the images and optical micrographs of the foams produced from the rice husk.

It is possible to visually verify that the formulations of the foams visually had an influence on the three-dimensional stiffness of the foams. With increasing amount of yeast in the CA-1 (Figure 4 (a)) and CA-1P foams (Figure 4 (c)) a foam with a larger pore structure was obtained in relation to the CA-2 foams (Figure 4 (e)) and CA-2P (Figure 4 (g)). Yuan et al. ${ }^{8}$ studied the influence of yeast concentration on carbon foams derived from wheat flour, and also observed the same structural behavior of the foams. According to the authors, yeast and water play a vital role during the formation of the pore structure. After adding water, the starches can be gelatinized and the proteins in the flour fully absorb the 

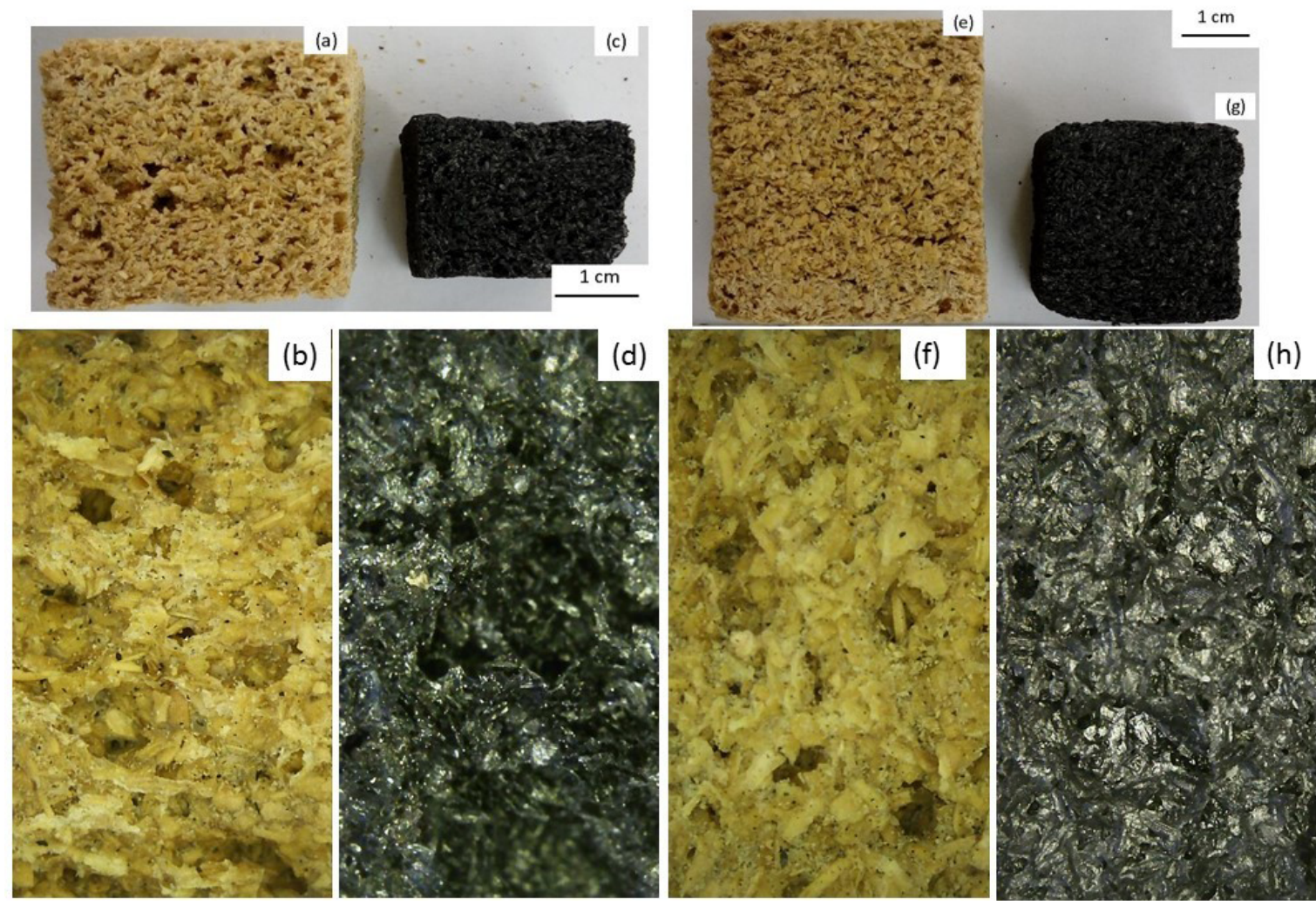

Figure 4. Photographs: (a) CA-1, (c) CA-1P, (e) CA-2 and (g) CA-2P. Optical micrographs: (b) CA-1, (d) CA-1P, (e) CA-2 and (h) CA-2P. Caption: CA-1 (7.5 g yeast foam), CA-1P (CA-1 foam after pyrolysis), CA-2 (5.0 g yeast foam) and CA-1P (CA-2 foam after pyrolysis).

water to form a gluten network structure. Meanwhile, the yeast produces and releases carbon dioxide gases to form pores as it disperses in the paste.

After pyrolysis under an inert atmosphere $\left(\mathrm{N}_{2}\right)$, the rice husk was transformed into carbon foam. The size of the foams reduces which was also observed by Yuan et al. ${ }^{8}$. According to the authors, the original shape of the pore structure remains, but its size reduces by about $50 \%$ in volume, which can be observed by comparing Figures 4 (a) and (c) for the foams with $7.5 \mathrm{~g}$ of yeast and Figures 4 (e) and (g) for the foams with $5.0 \mathrm{~g}$ of yeast. This process comprises two reactions, involving dehydration and carbonization, in which condensable gases are released.

During the vapor deposition process of VTES, a silane film is formed on the surface of the foam, which does not alter its morphology and thermal and physical properties. After treatment, the hydrogen bonds formed at the interface act as a separation system, preventing the fiber from interacting with the water present in the medium ${ }^{23}$.

In Figure 5, the apparent density results of the foams are presented. It is possible to verify that the variation in the amount of yeast used does interfere in the specific mass, that is to say, the lower the amount of yeast, the higher is the specific mass. This happen, because there is a smaller formation of pores in the structure.

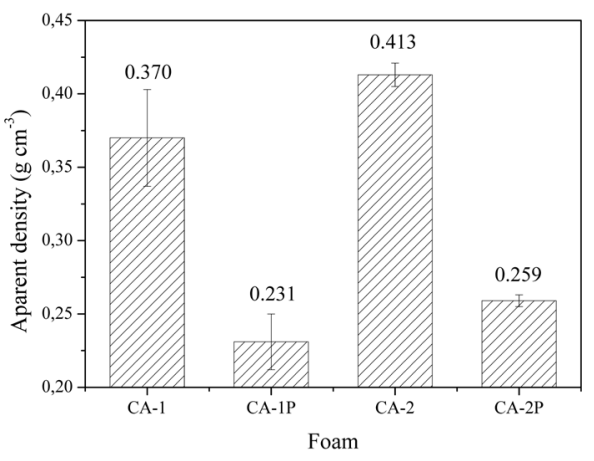

Figure 5. Apparent density of foams. Caption: CA-1 (7.5 g yeast foam), CA-1P (CA-1 foam after pyrolysis), CA-2 (5.0 g yeast foam) and CA-1P (CA-2 foam after pyrolysis).

It regards to the flame test conducted with the foams (before and after pyrolysis), which was presented visually through Figure 1, it is possible to relate it to the thermal analysis presented and discussed in Figure 3. The carbon foams present only one mass loss event below $100{ }^{\circ} \mathrm{C}$ due to the moisture present in the sample. After that, the mass loss ratio becomes constant, which shows that the organic matter (cellulose, hemicellulose and lignin) present in the rice husk was degraded during the pyrolysis process. The 
residual mass of the carbon foams was about $90 \%$, while the residual mass of the rice husk foam is approximately $20 \%$. This result shows that carbon foams have a higher thermal stability than rice husk foams, which is proved when the foams are exposed to direct flames. In the flame test (Figure 1) it was possible to visually perceive that the carbon foam does not burn when in contact with the flame. This is due to the pyrolysis carried out on rice husk foam, in which much of the organic matter present in the foam is carbonized, serving as an anti-flame treatment. The rice husk foam, on the other hand, when exposed to direct flame, burns completely.

The result found for the water contact angle test of the foams is presented in Table 1 .

Table 1. Water contact angle of rice husk and carbon foams.

\begin{tabular}{|c|c|c|}
\hline Foam & Photography assay & WCA \\
\hline CA-1 & 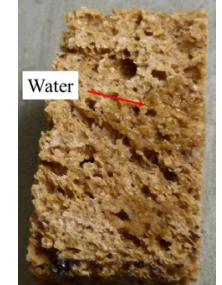 & $0^{\circ}$ \\
\hline
\end{tabular}

CA-1H

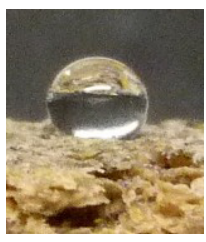

CA-1P

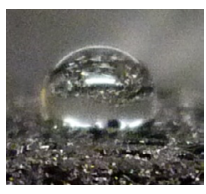

CA-2

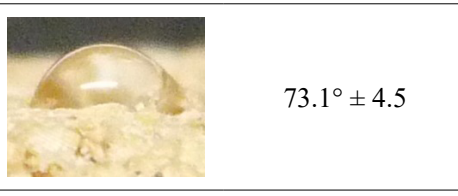

CA-2H

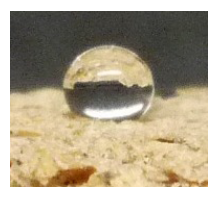

$125.7^{\circ} \pm 2.0$

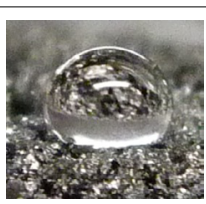

Table 1 shows that the CA-1 foam absorbs the water drop momentarily which prevents the contact angle from being measured. On the other hand, for the CA-2 foam, it was possible to measure the contact angle of water, because the structure had smaller pores, the water droplet remained under the surface for a few minutes and was then absorbed by the foam. This results shows that the two foams are hydrophilic, that is, have an affinity with water, thus justifying the need to perform chemical (vapor deposition) or thermal (pyrolysis) treatment for the modification of this characteristic.

By evaluating the treated surface foams, CA-1H and CA$2 \mathrm{H}$ were more efficient than CA-1P and CA-2P, especially in foams with the lowest amount of yeast used (CA-2H). However, both treatments were efficient for the hydrophobization of the foams because in all cases the contact angle was higher than $90^{\circ}$, thus classifying the foams as hydrophobic ${ }^{24}$.

The hydrophobicity demonstrated by the contact angle is corroborated by the water sorption capacity test of the foams, shown in Figure 6. The CA-1 and CA-2 foams have a higher water sorption capacity ( 2.14 and $2.57 \mathrm{~g} \mathrm{~g}^{-1}$, respectively) than the others, precisely because they do not have a hydrophobic surface, thus having more affinity with water.

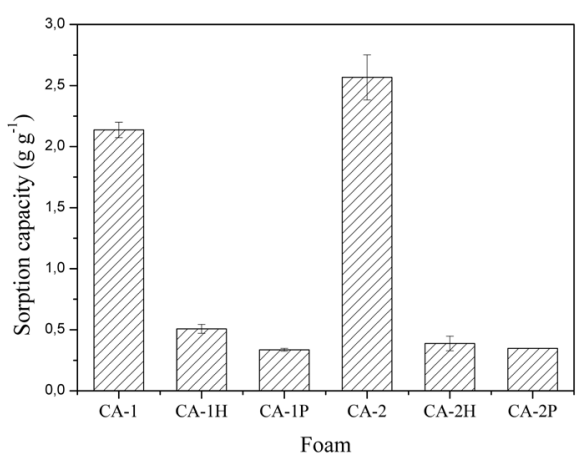

Figure 6. Water sorption capacity of rice husk and carbon foams.

The water sorption capacity of the surface treated foams did not show any difference between the chemical and thermal treatments. Even with the highest water contact angle, the $\mathrm{CA}-2 \mathrm{H}$ foam presented sorption capacity close to the other treated foams, about $0.5 \mathrm{~g}$ of water sorbed per gram of foam. This test shows that if exposed to a humid or rainy environment, heat treated or chemically treated foams would draw a lower amount of water than the wood foams, and thus delay degradation.

Figure 7 shows the thermal conductivity results of the rice husk and carbon foams. Formulation 1 foams (CA-1 and CA-1P) presented lower thermal conductivity than CA-2 and CA-2P foams, because CA-1 and CA-1P foams have larger pores (Figure 4) due to the higher amount of yeast used in this formulation. In comparing the rice husk and carbon foams, the rice husk foams presented lower thermal conductivity than the carbon foams, because after the pyrolysis process the amount of carbon present in the foams is higher, which causes the thermal conductivity. 


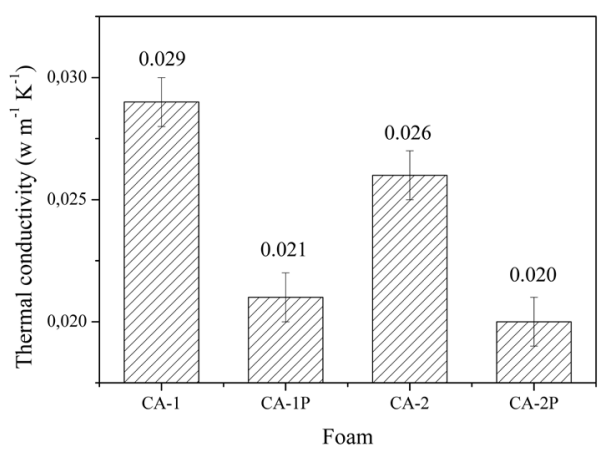

Figure 7. Thermal conductivity of foams. Caption: CA-1 (7.5 g yeast foam), CA-1P(CA-1 foam after pyrolysis), CA-2 (5.0 g yeast foam) and CA-1P (CA-2 foam after pyrolysis).

The foams produced by Yuan et al. ${ }^{8}$, with a specific mass of $0.09-0.23 \mathrm{~g} \mathrm{~cm}^{-3}$, presented thermal conductivity varying from 0.08 to $0.17 \mathrm{~W} \mathrm{~m}^{-1} \mathrm{~K}^{-1}$. According to the authors, after pyrolysis, the structure of the foams has less impurities. At the same time the carbon structure is aligned. Therefore, fewer defects and edges in the sample contribute to a higher heat transfer.

\section{Conclusion}

The carbon foams produced from the rice husk showed similar thermal conductivity to materials used commercially for thermal insulation. The methodology adopted in this study uses a combination of simple (agricultural residue and wheat flour) and environmentally friendly elements. In addition, it is, an easy process that does not require the use of reagents toxic to the environment. Considering that they have been resistant to direct flame, which makes them a potential anti-flame material preventing the spread of fire. In the comparison between the two methods of hydrophobizing rice husk foams (pyrolysis and vapor deposition of VTES), both treatments were positive regarding the modification of the hydrophilic to hydrophobic characteristic of the rice husk foams surface. contact greater than $90^{\circ}$. Besides that, carbon foams have the same ability to repel water/moisture as chemically treated foams. Thus, with the results found for carbon foams there are strong reasons to believe that the alternative product analyzed in this study is promising from a thermal insulation perspective.

\section{Acknowledgments}

The authors would like to express their gratitude to the Federal University of Rio Grande do Sul (UFRGS), the University of Caxias do Sul (UCS), the National Council for Scientific and Technological Development (CNPq) and the Foundation for Research Support of the State of Rio Grande do Sul (FAPERGS ).

\section{References}

1. Quispe I, Navia R, Kahhat R. Energy potential from rice husk through direct combustion and fast pyrolysis: A review. Waste Management. 2016;59:200-210.

2. Lazzari E, Schena T, Caetano M, Marcelo A, Tatiane C, Nunes A, et al. Classification of biomass through their pyrolytic bio-oil composition using FTIR and PCA analysis. Industrial Crops and Products. 2018;111:856-64.

3. António J, Tadeu A, Marques B, Almeida JAS, Pinto V. Application of rice husk in the development of new composite boards. Construction and Building Materials. 2018;176:432439 .

4. Zhang G, Chen Y, Chen Y, Guo H. Activated biomass carbon made from bamboo as electrode material for supercapacitors. Materials Research Bulletin. 2018;102:391-398.

5. Bakierska M, Molenda M, Majda D, Dziembaj R. Functional starch based carbon aerogels for energy applications. Procedia Engineering. 2014;98:14-19.

6. Tijani MM, Aqsha A, Mahinpey N. Development of oil-spill sorbent from straw biomass waste : Experiments and modeling studies. Journal of Environmental Management. 2016;171:166176.

7. Feng J, Nguyen ST, Fan Z, Duong HM. Advanced fabrication and oil absorption properties of super-hydrophobic recycled cellulose aerogels. Chemical Engineering Journal. 2015;270:168175.

8. Ye Y, Ding Y, Wang C, Xu F, Lin Z, Qin Y, et al. Multifunctional Stiff Carbon Foam Derived from Bread Multifunctional Stiff Carbon Foam Derived from Bread. ACS Applied Materials and Interfaces. 2016;8(26):16852-16861.

9. Jana P, Fierro V, Pizzi A, Celzard A. Biomass-derived, thermally conducting, carbon foams for seasonal thermal storage. Biomass and Bioenergy. 2014;67:312-318

10. Basu P. Biomass Gasification and Pyrolysis: Pratical Design and Theory. Pittsburgh: Eselvier Inc.; 2010.

11. Gallego NC, Klett JW. Carbon foams for thermal management. Carbon. 2003;41(7):1461-466.

12. Adhikari S, Nam H, Chakraborty JP. Conversion of Solid Wastes to Fuels and Chemicals Through Pyrolysis. In: Bhaskar T, Pandey A, Lee DJ, Khanal SK, editors. Waste Biorefinery: Potential and Perspectives. Amsterdam: Eselvier BV; 2018. p. 239-263.

13. Almeida SR. Pirólise rápida de casca de arroz : estudo de parâmetros e caracterização de produtos [Dissertação]. Porto Alegre: Universidade Federal do Rio Grande do Sul; 2010.

14. Perondi D, Polleto P, Restelatto D, Manera C, Silva JP, Junges J, et al. Steam gasification of poultry litter biochar for bio-syngas production. Process Safety and Environmental Protection. 2017;109:478-488. 
15. Lazzari LK, Zampieri VB, Zanini M, Zattera AJ, Baldasso C. Sorption capacity of hydrophobic cellulose cryogels silanized by two different methods. Cellulose. 2017;24(8):3421-3431.

16. McKendry P. Energy production from biomass (part 1): overview of biomass. Bioresource Technology. 2002;83(1):37-46.

17. Menya E, Olupot PW, Storz H, Lubwama M, Kiros Y. Production and performance of activated carbon from rice husks for removal of natural organic matter from water: A review. Chemical Engineering Research and Design. 2017;129:271-96.

18. Bakar MSA, Titiloye JO. Catalytic pyrolysis of rice husk for bio-oil production. Journal of Analytical and Applied Pyrolysis. 2013;103:362-368.

19. Fang M, Yang L, Chen G, Shi Z, Luo Z, Cen K. Experimental study on rice husk combustion in a circulating fluidized bed. Fuel Processing Technology. 2004;85(11):1273-1282.

20. Diniz J. Conversão térmica de casca de arroz à baixa temperatura: produção de bioóleo e resíduo sílico-carbonoso adsorvente
[Tese]. Santa Maria: Universidade Federal de Santa Maria; 2005.

21. Özsin G. Insights into pyrolysis and co-pyrolysis of biomass and polystyrene: Thermochemical behaviors, kinetics and evolved gas analysis. Energy Conversion and Management. 2017;149:675-85.

22. Dunnigan L, Ashman PJ, Zhang X, Kwong CW. Production of biochar from rice husk: Particulate emissions from the combustion of raw pyrolysis volatiles. Journal of Cleaner Production. 2018;172:1639-1645.

23. Salon MCB, Abdelmouleh M, Boufi S, Belgacem MN, Gandini A. Silane adsorption onto cellulose fibers: Hydrolysis and condensation reactions. Journal of Colloids and Interface Science. 2005;289(1):249-261.

24. Aegerter MA, Leventis N, Koebel MM. Aerogels Handbook. New York: Springer-Verlag; 2011. 